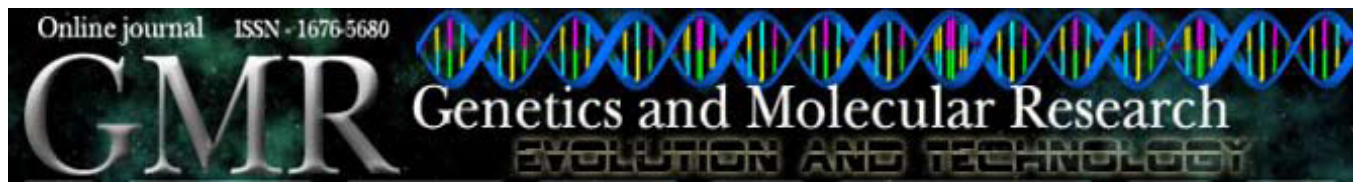

\title{
Lack of association between MD-2 promoter gene variants and tuberculosis
}

\author{
Y. Xue ${ }^{1,2 *}$, Z.Q. Zhao ${ }^{2 *}$, D. Hong', M.Y. Zhao' ${ }^{1}$ Y.X. Zhang', H.J. Wang ${ }^{3}$, \\ Y. Wang ${ }^{4}$ and J.C. Li $^{1}$ \\ 'Institute of Cell Biology, School of Medicine, Zhejiang University,Hangzhou, China \\ ${ }^{2}$ Henan University of Science and Technology, Luoyang, China \\ ${ }^{3}$ The Sixth Hospital of Shaoxing, Shaoxing, China \\ ${ }^{4}$ Jilin Academy of Traditional Chinese Medicine Sciences, Changchun, China \\ *These authors contributed equally to this study. \\ Corresponding author: J.C. Li \\ E-mail: ji-chengli@hotmail.com / zhaozhanqin@126.com
}

Genet. Mol. Res. 9 (3): 1584-1590 (2010)

Received February 15, 2010

Accepted April 5, 2010

Published August 17, 2010

DOI 10.4238/vol9-3gmr771

\begin{abstract}
Myeloid differentiation-2 (MD-2) is an essential component of the CD14-TLR4/MD-2 receptor complex involved in microbial cell wall component recognition during infection. Genetic variations in the MD-2 gene may influence human susceptibility to infectious diseases. To date, a predisposition of MD-2 gene variants to contract tuberculosis has not been reported. We investigated whether MD-2 gene polymorphisms were associated with the development of tuberculosis in a Chinese population. The six common polymorphisms (rs11465996, rs1809442, rs1809441, rs1809440, rs16938754, and rs7842342) within the MD-2 gene promoter region were all detected in 259 patients with tuberculosis and 276 healthy control subjects by DNA sequencing. None of the allelic frequencies, haplotype patterns or genotype distributions of the assayed polymorphisms was found to be significantly different between patients and controls $(\mathrm{P}>0.05)$. We conclude that these gene variants in the MD-2 gene promoter region are not associated with tuberculosis, and apparently do not play a role in susceptibility to tuberculosis in the Chinese population.
\end{abstract}

Key words: MD-2; Tuberculosis; Single-nucleotide polymorphisms; Disease susceptibility 


\section{INTRODUCTION}

Tuberculosis (TB) causes significant morbidity and mortality throughout the world, particularly in resource-poor countries. Although one-third of the world's population is infected with Mycobacterium tuberculosis (Mtb), only 5-10\% of those infected will ever develop the active disease (Rosman and Oner-Eyupoglu, 1998). Susceptibility to disease can be influenced by both genetic predisposition and environmental factors (Cooke and Hill, 2001). Genetic variability may influence not only host susceptibility to active TB but also host responses to treatment. Polymorphisms in many different host genes with a potential role in TB susceptibility have been studied (Moller et al., 2010), and the genes involved in the Toll-like receptor (TLR) signaling pathway are of great interest because of their front-line role in the initiation of innate immunity against Mtb (Ma et al., 2007; Davila et al., 2008; Velez et al, 2010).

Myeloid differentiation-2 (MD-2) is considered to be an important accessory protein in TLR signaling. This protein acts as an essential component of the CD14-TLR4/MD-2 receptor complex for microbial cell wall component recognition (such as lipopolysaccharide) during infection and is a critical factor for cell surface expression of TLR4 (Visintin et al., 2006; Nishitani et al., 2009). In addition to bacterial recognition and activation of inflammatory cascades, MD-2 has recently been shown to be an opsonin and an acute-phase protein after infection by several types of pathogens (Tissieres et al., 2008; Wolfs et al., 2008; Sandanger et al., 2009). MD-2 knockout mice were reported to have increased resistance to endotoxemia but increased susceptibility to Salmonella typhimurium infection (Nagai et al., 2002). So far, several polymorphisms in the genes encoding CD14 and TLR4 have been considered to determine susceptibility to TB (Pacheco et al., 2004; Ferwerda et al., 2007; Rosas-Taraco et al., 2007). In view of the functional significance of genetic polymorphisms in CD14 and TLR4 genes, and their close relationship with MD-2, we hypothesized that certain polymorphisms in the MD-2 gene may also influence the development of TB.

The promoter of the MD-2 gene was reported to be located within the 2-kb sequence upstream of the translational start site (Abreu et al., 20025). This DNA region contains all six known single-nucleotide polymorphism (SNP) sites within this gene (C-1625G, C-1201G, G1174T, A-1064G, T-538G, and T-475A) according to data from a publicly available database (dbSNP, http://www.ncbi.nlm.nih.gov/SNP). However, the effect of these genetic polymorphisms in the MD-2 promoter region on the development of TB is unknown. To our knowledge, this is the first study to investigate whether polymorphic sites in the MD-2 promoter region correlate with the development of TB in a Chinese population.

\section{MATERIAL AND METHODS}

\section{Patients and controls}

In total, 259 unrelated patients diagnosed with TB (confirmed by clinical, radiological and bacteriological examinations) were enrolled in the original study group. All TB sufferers were undergoing standard TB treatment at the TB clinic in the Sixth Hospital in Shaoxing or the Hangzhou Red Cross Hospital in Hangzhou from October 2005 to July 2008. Patients were excluded if they tested positive for HIV or were being treated with immunosuppressive agents. The control group comprised 276 healthy, unrelated blood donors, with no history of TB or 
other immune diseases. All control subjects were from the same ethnic Han population and geographical origin, and were living in the same region as the patients with TB (Southeast China). This study was approved by the Ethics Committees of the Faculty of Medicine (Zhejiang University, China), and informed consent was obtained from all subjects before blood sampling.

\section{Genotyping}

Polymorphisms in the MD-2 promoter region were detected by polymerase chain reaction (PCR), followed by direct sequencing. Genomic DNAs were extracted from the blood samples by the salting out method (Rousseau et al., 1994). The PCR primers included forward 1: 5'-ATTTTCTTCTTAAGTGTGCAGAT-3' and reverse 1: 5'-TCCACGGCCCCCAGAGGA T-3'; forward 2: 5'-TGGGGGCCGTGGACCAGTA-3' and reverse 2: 5'-TTTCAGTAAGCAG AAAAGATTTAAC-3'. The PCR products covered the entire 2-kb promoter region. PCR was performed under the following conditions: denaturation at $94^{\circ} \mathrm{C}$ for $3 \mathrm{~min}$, followed by 34 cycles at $94^{\circ} \mathrm{C}$ for $50 \mathrm{~s}, 58^{\circ} \mathrm{C}$ for $30 \mathrm{~s}$, and $72^{\circ} \mathrm{C}$ for $1 \mathrm{~min}$, with a final extension at $72^{\circ} \mathrm{C}$ for $5 \mathrm{~min}$. The amplified products were purified and then analyzed by gene scanning with an ABI 3100 sequencer (Applied Biosystems, Carlsbad, CA, USA).

\section{Statistical analysis}

Chi-squared tests were used to compare allele, genotype and haplotype distribution in TB patients and controls. Odds ratios and $95 \%$ confidence intervals were also calculated. The analysis used a two-tailed estimation of significance. Values of $\mathrm{P}<0.05$ were considered to be statistically significant. Hardy-Weinberg equilibrium (HWE) was also assessed using a $\chi^{2}$ test in each group. D' and $\mathrm{r}^{2}$ were calculated to evaluate the magnitude of linkage disequilibrium. SNPstats (http:/ bioinfo.iconcologia.net/SNPstats) and SPSS 15.0 (SPSS, Chicago, IL, USA) softwares were used for the statistical analysis.

\section{RESULTS}

\section{Characteristics of participants}

Clinical characteristics of patients and controls are illustrated in Table 1.

\begin{tabular}{|c|c|c|c|}
\hline & $\begin{array}{l}\text { TB group } \\
(\mathrm{N}=259)\end{array}$ & $\begin{array}{l}\text { Control group } \\
(\mathrm{N}=276)\end{array}$ & $P$ \\
\hline Age in years, range (mean \pm SD) & $18-65(40.1 \pm 14.7)$ & $20-60(37.0 \pm 12.3)$ & $0.423^{\mathrm{a}}$ \\
\hline Gender: female & $101(39.0 \%)$ & $114(41.3 \%)$ & $0.586^{\mathrm{b}}$ \\
\hline Body mass index $($ mean $\pm \mathrm{SD})$ & $20.7 \pm 3.4$ & $23.0 \pm 3.7$ & $0.083^{\mathrm{a}}$ \\
\hline Pulmonary TB & 238 & ND & - \\
\hline Extrapulmonary $\mathrm{TB}^{\mathrm{c}}$ & 21 & ND & - \\
\hline Tuberculin skin test $(>10 \mathrm{~mm})$ & $185(71.4 \%)$ & ND & - \\
\hline Presence of TB history & $30(11.6 \%)$ & $21(7.6)$ & $0.118^{\mathrm{b}}$ \\
\hline BCG vaccination & $129(49.8 \%)$ & $156(56.5 \%)$ & $0.120^{\mathrm{b}}$ \\
\hline
\end{tabular}

Data are reported as number with percent in parentheses, unless otherwise stated. $\mathrm{ND}=$ not determined. ${ }^{\mathrm{a} D i f f e r e n c e}$ between patients and controls ( $t$-test). ${ }^{b}$ Difference between patients and controls $\left(\chi^{2}\right.$ test). ${ }^{c}$ Extrapulmonary TB includes lymphadenitis and pleural, bone and renal tuberculosis. 
The analysis included 276 healthy controls and 259 TB patients. The average age was $40.1 \pm 14.7$ years (range: $18-65$ years) in the TB group, and $37.0 \pm 12.3$ years (range: $20-60$ years) in the control group. Females constituted $39.0 \%$ of the TB group and $41.3 \%$ of the control group. Mean age, gender or body mass index did not differ between patients and controls $(\mathrm{P}>0.05)$.

\section{Allele, haplotype and genotype frequencies}

The frequencies of alleles, haplotypes and genotypes of the MD-2 gene promoter region polymorphisms in TB patients and controls are shown in Tables 2, 3 and 4, respectively. All SNPs were in HWE $(\mathrm{P}>0.05)$ in controls (Table 2). No genetic variation was observed at positions -538 and -475 (Table 2). Positions $-1625,-1201,-1174$, and -1064 were found to be in extremely tight linkage disequilibrium (D'>0.9997, $\mathrm{r}^{2}>0.7029, \mathrm{P}<0.0001$ ) (Figure 1). No significant differences between patients and controls were observed in allele, haplotype or genotype distribution $(\mathrm{P}>0.05)$ (Tables 2, 3 and 4).

\begin{tabular}{|c|c|c|c|c|c|c|c|}
\hline \multirow[t]{2}{*}{ SNP ID } & \multirow[t]{2}{*}{ Position } & \multirow[t]{2}{*}{ Allele } & \multicolumn{2}{|c|}{ Allelic frequency } & \multicolumn{2}{|c|}{ Statistics } & \multirow[t]{2}{*}{ OR $(95 \% \mathrm{CI})$} \\
\hline & & & Patients, N (Freq) & Controls, N (Freq) & $\chi^{2}$ & $\mathrm{P}$ & \\
\hline $\begin{array}{l}\text { rs11465996 } \\
\text { HWE (P) }\end{array}$ & C-1625G & $\mathrm{C}$ & $422(0.81)$ & $\begin{array}{c}447 \text { (0.81) } \\
1\end{array}$ & 0.042 & 0.838 & $1.033(0.760-1.404)$ \\
\hline $\begin{array}{l}\text { rs1809442 } \\
\text { HWE (P) }\end{array}$ & C-1201G & $\mathrm{C}$ & $358(0.69)$ & $\begin{array}{c}395(0.72) \\
0.24\end{array}$ & 0.767 & 0.385 & $0.889(0.684-1.156)$ \\
\hline $\begin{array}{l}\text { rs1809441 } \\
\text { HWE (P) }\end{array}$ & G-1174T & G & $358(0.69)$ & $\begin{array}{c}395(0.72) \\
0.24\end{array}$ & 0.767 & 0.385 & $0.889(0.684-1.156)$ \\
\hline $\begin{array}{l}\text { rs } 1809440 \\
\text { HWE (P) }\end{array}$ & A-1064G & A & $350(0.68)$ & $\begin{array}{c}379(0.69) \\
0.40\end{array}$ & 0.147 & 0.743 & $0.951(0.735-1.230)$ \\
\hline $\begin{array}{l}\text { rs16938754 } \\
\text { HWE (P) }\end{array}$ & $\mathrm{T}-538 \mathrm{G}$ & $\mathrm{T}$ & $518(1.00)$ & $\begin{array}{c}552(1.00) \\
-\end{array}$ & - & - & - \\
\hline $\begin{array}{l}\text { rs7842342 } \\
\text { HWE (P) }\end{array}$ & $\mathrm{T}-475 \mathrm{~A}$ & $\mathrm{~T}$ & $518(1.00)$ & $\begin{array}{c}552(1.00) \\
-\end{array}$ & - & - & - \\
\hline
\end{tabular}

$\mathrm{SNP}=$ single-nucleotide polymorphism; $\mathrm{HWE}=$ Hardy-Weinberg equilibrium; $\mathrm{OR}=$ odds ratio; $\mathrm{CI}=$ confidence interval; $\mathrm{N}=$ number of alleles; Freq = frequency.

Table 3. Genotype frequencies of polymorphic variants of the MD-2 gene in patients with tuberculosis $(\mathrm{N}=$ 259) and healthy controls $(\mathrm{N}=276)$.

\begin{tabular}{|c|c|c|c|c|c|}
\hline SNP site & Genotype & $\begin{array}{l}\text { Patients } \\
\text { N (Freq) }\end{array}$ & $\begin{array}{l}\text { Controls } \\
\mathrm{N} \text { (Freq) }\end{array}$ & $\mathrm{P}$ & OR $(95 \% \mathrm{CI})$ \\
\hline \multirow[t]{3}{*}{-1625} & $\mathrm{CC}$ & $177(0.683)$ & $181(0.656)$ & \multirow{3}{*}{0.36} & 1 \\
\hline & CG & $68(0.262)$ & $85(0.308)$ & & $1.22(0.84-1.79)$ \\
\hline & GG & $14(0.054)$ & $10(0.036)$ & & $0.70(0.30-1.61)$ \\
\hline \multirow[t]{3}{*}{-1201} & $\mathrm{CC}$ & $121(0.467)$ & $137(0.496)$ & \multirow{3}{*}{0.62} & 1 \\
\hline & CG & $116(0.448)$ & $121(0.438)$ & & $0.92(0.65-1.31)$ \\
\hline & GG & $22(0.085)$ & $18(0.065)$ & & $0.72(0.37-1.41)$ \\
\hline \multirow[t]{3}{*}{-1174} & GG & $121(0.467)$ & $137(0.496)$ & \multirow{3}{*}{0.62} & 1 \\
\hline & GT & $116(0.448)$ & $121(0.438)$ & & $0.92(0.65-1.31)$ \\
\hline & $\mathrm{TT}$ & $22(0.085)$ & $18(0.065)$ & & $0.72(0.37-1.41)$ \\
\hline \multirow[t]{3}{*}{-1064} & AA & $119(0.460)$ & $133(0.482)$ & \multirow{3}{*}{0.86} & 1 \\
\hline & AG & $112(0.432)$ & $113(0.409)$ & & $0.90(0.63-1.29)$ \\
\hline & GG & $28(0.108)$ & $30(0.109)$ & & $0.96(0.54-1.70)$ \\
\hline
\end{tabular}

$\mathrm{SNP}=$ single-nucleotide polymorphism; $\mathrm{OR}=$ odds ratio $; \mathrm{CI}=$ confidence interval; $\mathrm{N}=$ number of alleles; Freq = frequency. 
Table 4. Haplotype frequencies of polymorphic variants of the MD-2 gene in patients with tuberculosis $(\mathrm{N}=$ $259)$ and healthy controls $(\mathrm{N}=276)$.

\begin{tabular}{|c|c|c|c|c|c|c|c|c|}
\hline \multirow[t]{2}{*}{ Haplotype } & \multicolumn{4}{|c|}{ Allele at marker } & \multirow{2}{*}{$\begin{array}{l}\text { Patients } \\
\text { (Freq) }\end{array}$} & \multirow{2}{*}{$\begin{array}{c}\text { Controls } \\
\text { (Freq) }\end{array}$} & \multirow[t]{2}{*}{$P$} & \multirow[t]{2}{*}{ OR $(95 \% \mathrm{CI})$} \\
\hline & -1625 & -1201 & -1174 & -1064 & & & & \\
\hline 1 & $\mathrm{C}$ & $\mathrm{C}$ & G & A & 0.6757 & 0.6866 & - & 1 \\
\hline 2 & G & G & $\mathrm{T}$ & G & 0.1853 & 0.1902 & 0.85 & $0.97(0.71-1.32)$ \\
\hline 3 & $\mathrm{C}$ & G & $\mathrm{T}$ & G & 0.1236 & 0.0942 & 0.14 & $0.75(0.51-1.10)$ \\
\hline 4 & $\mathrm{C}$ & $\mathrm{C}$ & G & $\mathrm{G}$ & 0.0154 & 0.0290 & 0.24 & $1.54(0.75-3.16)$ \\
\hline
\end{tabular}

Freq $=$ frequency of haplotype; $\mathrm{OR}=$ odds ratio; $\mathrm{CI}=$ confidence interval.

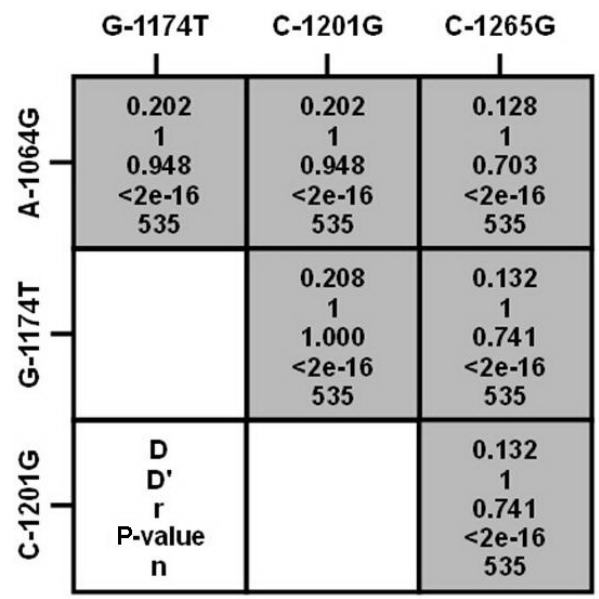

Figure 1. Linkage disequilibrium analysis of single-nucleotide polymorphisms (SNPs) in the MD-2 gene promoter region. The number at the intersection of each pair of SNPs represents the pairwise D, D', $\mathrm{r}^{2}$, and P values between two SNPs. Values of D'> 0.75 were considered to be strong pairwise linkage disequilibrium.

\section{DISCUSSION}

In this study, we analyzed the association between polymorphisms in the proximal promoter region of the MD-2 gene and TB. However, no statistically significant differences were detected between the allele, haplotype and genotype distributions of these SNPs when comparing TB patients with healthy controls. Our results do not support the hypothesis that these genetic polymorphisms in the MD-2 promoter region contribute significantly to human susceptibility to TB.

Although the importance of TLR signaling in the course of Mtb infection is known, the role of the TLR4 pathway remains controversial. TLR4 signaling was reported to be required for mounting a protective response during chronic Mtb infection, and in elimination of mycobacteria (Abel et al., 2002; Branger et al., 2004). On the other hand, it was also reported that TLR4 is not required for immunity against TB (Kamath et al., 2003; Shim et al., 2003). As an accessory protein in TLR4 signaling, MD-2 could play an important role in cell surface expression of TLR4 and recognition of microbial components (such as mycobacterial heat shock proteins) (Bulut et al., 2005; Visintin et al., 2006; Nishitani et al., 2009). However, Mtbinduced macrophage activation was not augmented by overexpression of ectopic MD-2, and 
cells expressing a lipopolysaccharide-unresponsive MD-2 mutant responded normally to Mtb (Means et al., 2001). Therefore, TLR4 signaling, and the accessory protein MD-2, may not play a significant role in immunity to Mtb compared with other TLR signaling pathways, such as TLR2 signaling (Jo et al., 2007; Drage et al., 2009; Velez et al., 2010). This is supported by the findings of our study, in which genetic variation in the MD-2 gene promoter region was found to be unrelated to susceptibility to TB.

According to data from a publicly available database (dbSNP, http://www.ncbi.nlm. nih.gov/SNP), the allelic frequencies of the genetic variations in the MD-2 gene promoter region in individuals of different ethnicities are not identical (for example, rs11465996 (-1625) G-allele: 0.358 in Europeans, 0.222 in Asians and 0.167 in Africans). These differences may result in diverse genetic roles of these polymorphisms in different populations in the context of certain diseases. Therefore, additional studies are needed to clarify the exact role of these polymorphisms in the pathogenesis of TB in a range of other ethnic populations. In addition, it has been reported that polymorphisms in the MD-2 promoter region do have a significant influence on MD-2 expression levels in an in vitro study, and the C-1625G polymorphism has been demonstrated to be associated with organ dysfunction or sepsis after major trauma $(\mathrm{Gu}$ et al., 2007). Therefore, although no such association was found in TB disease, this kind of association may exist in other Gram-negative bacterial infectious diseases, in which the host immune response is more highly dependent on the TLR4/MD-2 signaling pathway.

In brief, our results suggest that polymorphisms in the MD-2 promoter region are not associated with TB, and may not play a major role in susceptibility to TB in a Chinese population.

\section{ACKNOWLEDGMENTS}

Research supported by grants from the National Fund for Fostering Talents of Basic Science (NFFTBS, \#J0730856 and \#J0830833) and National Sci-tech Important Special Projects (\#2008ZX10005-010).

\section{REFERENCES}

Abel B, Thieblemont N, Quesniaux VJ, Brown N, et al. (2002). Toll-like receptor 4 expression is required to control chronic Mycobacterium tuberculosis infection in mice. J. Immunol. 169: 3155-3162.

Abreu MT, Arnold ET, Thomas LS, Gonsky R, et al. (2002). TLR4 and MD-2 expression is regulated by immunemediated signals in human intestinal epithelial cells. J. Biol. Chem. 277: 20431-20437.

Branger J, Leemans JC, Florquin S, Weijer S, et al. (2004). Toll-like receptor 4 plays a protective role in pulmonary tuberculosis in mice. Int. Immunol. 16: 509-516.

Bulut Y, Michelsen KS, Hayrapetian L, Naiki Y, et al. (2005). Mycobacterium tuberculosis heat shock proteins use diverse Toll-like receptor pathways to activate pro-inflammatory signals. J. Biol. Chem. 280: 20961-20967.

Cooke GS and Hill AV (2001). Genetics of susceptibility to human infectious disease. Nat. Rev. Genet. 2: 967-977.

Davila S, Hibberd ML, Hari DR, Wong HE, et al. (2008). Genetic association and expression studies indicate a role of Toll-like receptor 8 in pulmonary tuberculosis. PLoS. Genet. 4: e1000218.

Drage MG, Pecora ND, Hise AG, Febbraio M, et al. (2009). TLR2 and its co-receptors determine responses of macrophages and dendritic cells to lipoproteins of Mycobacterium tuberculosis. Cell Immunol. 258: 29-37.

Ferwerda B, Kibiki GS, Netea MG, Dolmans WM, et al. (2007). The Toll-like receptor 4 Asp299Gly variant and tuberculosis susceptibility in HIV-infected patients in Tanzania. AIDS 21: 1375-1377.

Gu W, Shan YA, Zhou J, Jiang DP, et al. (2007). Functional significance of gene polymorphisms in the promoter of myeloid differentiation-2. Ann. Surg. 246: 151-158.

Jo EK, Yang CS, Choi CH and Harding CV (2007). Intracellular signalling cascades regulating innate immune responses to Mycobacteria: branching out from Toll-like receptors. Cell Microbiol. 9: 1087-1098. 
Kamath AB, Alt J, Debbabi H and Behar SM (2003). Toll-like receptor 4-defective C3H/HeJ mice are not more susceptible than other $\mathrm{C} 3 \mathrm{H}$ substrains to infection with Mycobacterium tuberculosis. Infect. Immun. 71: 4112-4118.

Ma X, Liu Y, Gowen BB, Graviss EA, et al. (2007). Full-exon resequencing reveals Toll-like receptor variants contribute to human susceptibility to tuberculosis disease. PLoS. One 2: e1318.

Means TK, Jones BW, Schromm AB, Shurtleff BA, et al. (2001). Differential effects of a Toll-like receptor antagonist on Mycobacterium tuberculosis-induced macrophage responses. J. Immunol. 166: 4074-4082.

Moller M, de Wit E and Hoal EG (2010). Past, present and future directions in human genetic susceptibility to tuberculosis. FEMS Immunol. Med. Microbiol. 58: 3-26.

Nagai Y, Akashi S, Nagafuku M, Ogata M, et al. (2002). Essential role of MD-2 in LPS responsiveness and TLR4 distribution. Nat. Immunol. 3: 667-672.

Nishitani C, Takahashi M, Mitsuzawa H, Shimizu T, et al. (2009). Mutational analysis of Cys(88) of Toll-like receptor 4 highlights the critical role of MD-2 in cell surface receptor expression. Int. Immunol. 21: 925-934.

Pacheco E, Fonseca C, Montes C, Zabaleta J, et al. (2004). CD14 gene promoter polymorphism in different clinical forms of tuberculosis. FEMS Immunol. Med. Microbiol. 40: 207-213.

Rosas-Taraco AG, Revol A, Salinas-Carmona MC, Rendon A, et al. (2007). CD14 C(-159)T polymorphism is a risk factor for development of pulmonary tuberculosis. J. Infect. Dis. 196: 1698-1706.

Rosman MD and Oner-Eyupoglu AF (1998). Clinical Presentation and Treatment of Tuberculosis. In: Fishman's Pulmonary Diseases and Disorders (Fishman AP, ed.). McGraw-Hill, New York, 2483-2502.

Rousseau F, Rehel R, Rouillard P, DeGranpre P, et al. (1994). High throughput and economical mutation detection and RFLP analysis using a minimethod for DNA preparation from whole blood and acrylamide gel electrophoresis. Hum. Mutat. 4: 51-54.

Sandanger O, Ryan L, Bohnhorst J, Iversen AC, et al. (2009). IL-10 enhances MD-2 and CD14 expression in monocytes and the proteins are increased and correlated in HIV-infected patients. J. Immunol. 182: 588-595.

Shim TS, Turner OC and Orme IM (2003). Toll-like receptor 4 plays no role in susceptibility of mice to Mycobacterium tuberculosis infection. Tuberculosis 83: 367-371.

Tissieres P, Dunn-Siegrist I, Schappi M, Elson G, et al. (2008). Soluble MD-2 is an acute-phase protein and an opsonin for Gram-negative bacteria. Blood 111: 2122-2131.

Velez DR, Wejse C, Stryjewski ME, Abbate E, et al. (2010). Variants in Toll-like receptors 2 and 9 influence susceptibility to pulmonary tuberculosis in Caucasians, African-Americans, and West Africans. Hum. Genet. 127: 65-73.

Visintin A, Iliev DB, Monks BG, Halmen KA, et al. (2006). MD-2. Immunobiology 211: 437-447.

Wolfs TG, Dunn-Siegrist I, van't Veer C, Hodin CM, et al. (2008). Increased release of sMD-2 during human endotoxemia and sepsis: a role for endothelial cells. Mol. Immunol. 45: 3268-3277. 